\title{
A Review: Study on Identity in Mathematics Education
}

\section{Lovneesh Sharma ${ }^{1}$ Rashmi $^{2}$ Nileshwar Taak ${ }^{3}$}

\author{
${ }^{1}$ Civil Engineering Department, Chandigarh University \\ ${ }^{2}$ Mathematics Department, Chandigarh University \\ ${ }^{3}$ Civil Engineering Department, Chandigarh University \\ ${ }^{1}$ lovneeshsharma39@gmail.com, ${ }^{2}$ rashmi25sharma1997@gmail.com,3nileshwartaak2050@gmail.com
}

Article History: Received: 11 January 2021; Accepted: 27 February 2021; Published online: 5 April 2021

\begin{abstract}
This paper talks about the writing on direction in Science instruction distributed papers throughout the most recent twenty years. It examination the hypothetical system, investigation technique and distinguishing proof ideas, offering an analysis instead of a survey of the writing. A sum of 188 distribution from 85 separate diaries are dissected in the investigation. This survey shows that help for well-known reactions in this field of examination is inadequate in portrayals of the possibility of identity and demonstrates that taking a shot at this subject is frequently actually contradictory. Likewise, work here can emerge out of two unmistakable standards. Credibility could be viewed as an occasion and match inside a sociological structure, or it very well may be viewed as a creation, fitted inside a mental system. The idea of way of life as something we do, as an occasion, and specifically as a socially developed, is supported in this paper. At last, proposals for potential headings in character research are made.

Keywords: Performative, Mathematics instruction, Identity
\end{abstract}

\section{Introduction}

On the off chance that academic work is a discussion, at that point character is an everyday topic, having appreciated an emission of exploration and discussion in science training in the course of recent many years (Black et al.) (Cobb, Gresalfi, \& Hodge) and shaping the focal point of a considerably more effective subject. Zeroing in on character issues in arithmetic training, this examination is helpful for an assortment of reasons. It will permit us to consider science with a certain goal in mind, for example the recognizable proof of as a missing connection in the dynamic division among learning and its social and financial setting(Sfard \& Prusak). It identifies with issues of intensity and introduction and along these lines to questions with respect to value (Gutiérrez). It likewise drives us to think about the participatory attributes of members, for example, looking at why individuals can decide to seek after or pull out the investigation of arithmetic (Black et al.) (Chronaki).Character is an adaptable focal point; one can zoom in to the measure of communication between people or extend out to take a gander at the bigger social and monetary setting (de Freitas). We should center at the more extensive setting, with the end goal that, the issues of science learning by and large. We should take a gander at the viewpoints of specific gatherings of individuals and the issues of fairness. Or then again we can consider others level and look to grasp the relationship of understudies to science. Character, whatever the zoom level, offers a crystal through which we can assess, perceive and destroy a circumstance(Stinson \& Bullock) (Bernstein) (Boaler).

There is anyway a lot of applied and empiric exploration regarding this matter that doesn't show away from or comprehension of how character is utilized and in certain occasions, doesn't have an idea by any stretch of the imagination(Bishop)(Andersson).

Without even a consciousness of the observations, how might we take part in a beneficial conversation here? How might we create on the thoughts of others and make a superior comprehension of this subject without an average language or portrayal of the term? The Seventh Mathematics Education in Society Conference held in Cape town, South Africa, 2013 included more conspicuous evidence records than some other wide theme1 and moreover a component with respect to the issue(Bishop)(Holstein \& Gubrium). Notwithstanding the numerous basic philosophical directions of the gathering members, there was little collaboration and some contradiction between the various positions taken by the moderators. Such an examination offers an occasion to look at the social and political issues About how character is utilized, as has been brought up in this specific circumstance (Mead).The objective of this writing audit is to talk about composition inside our field to investigate how we utilize the possibility of personality in hypothetically and observationally study (Erikson). For this examination, I played out a methodical pursuit of the writing to get a wide example in a non-one-sided way, to mirror the 
manner in which we expound on character in arithmetic instruction. In doing as such, I wanted to comprehend the various ways we use character in our order and find new headings for this examination.

The conclusion of this article will be organized in the accompanying way. Second, I plot the cycles that I used to obtain an example. Next, I'm introducing insights that depict this writing. I am following this with a synopsis and conversation of the different manners by which character is depicted by specialists in arithmetic training papers, creating verification of the restricting and conflicting perspectives inborn in our order. I close with a glance at future headings for research in character inside science instruction.

\section{Method}

I began by characterizing a portion of the essential instructive information bases accessible to me. I have chosen five information bases to guarantee that I have gotten huge inclusion of the hits as I continued looking for arithmetic schooling writing on personality. My pursuit standard inside these information bases was the equivalent and as follows: science and training in any field and character in the theoretical.

The strategy utilized here has a scope of restrictions. Despite the fact that the utilization of five information bases guaranteed a wide scope of distributions, there was next to no duplication. This demonstrates that more papers of importance would have restored the extension of the hunt to considerably more information bases. Likewise, the later papers of 2014 have not yet been accessible. Nonetheless, it is accepted that the articles discovered were agent. All significant English-language diaries in the field were incorporated and the determination was not one-sided. The choice to incorporate just diary articles is restricted as there is a lot of writing that propels our thoughts on character distributed in different gatherings, specifically meeting procedures and books or book parts. Numerical Relations in Education: Identities and Participation (Chazan, Brantlinger, Clark, \& Edwards) and Mathematics Teachers: Identity and Identifications (Chronaki), for instance, provoked various audits in scholarly diaries. These are plainly huge works, yet are excluded from this audit.

My monolingualism has made a further constraint. Just the survey of the articles written in Identity Research in Mathematics Education English has created an only Western perspective on the idea. This is something that should be viewed as when perusing the outcomes and translations. I Bread each article trying to pick up understanding into the manner in which the writer's personality was perceived I've been searching for away from about the meaning of character. At the point when the work was referred to, I focused on the motivation behind the reference, regardless of whether essentially referencing another work in character or assisting with building up the idea of personality utilized by the creator. When perusing the articles, I was especially basic regarding whether the strategies, information examination or ends were predictable with the definitions or hypothetical system clarified by the writers (Kaasila, Hannula, \& Laine). I perceive that there are a wide range of basic glasses that can be worn when perusing crafted by others and my attention on these viewpoints will have blinded me to other possible territories of analysis (Holstein \& Gubrium). While dissecting the articles, I took a gander at the accompanying: the time of distribution, the diary of distribution, the area of the investigation, the sort of study, the quantity of members whose personality was examined, regardless of whether the members came from a particular social gathering (for instance, guys, Latino understudies, metropolitan youngsters) (Mead), the definition of identity given, and finally, which other authors were drawn from various papers.

\section{Characterizing identity articles:}

Statistics Increased numbers of publications confirm that the identity of study in mathematics education is very topical (see Fig. 1).In the event that the 1980s and 1990s saw a social move in science training research, the 2000s and past appear to recommend a personality move inside the social points of view of our order. Note that since the latest diary issues were not accessible in the information bases, the decrease in 2014 is probably going to be counterfeit. Ongoing exploration in science schooling diaries affirms that thus, around 2014 character articles are absent from the example(Heyd-Metzuyanim \& Sfard) 


\section{Mathematics identity articles published each year}

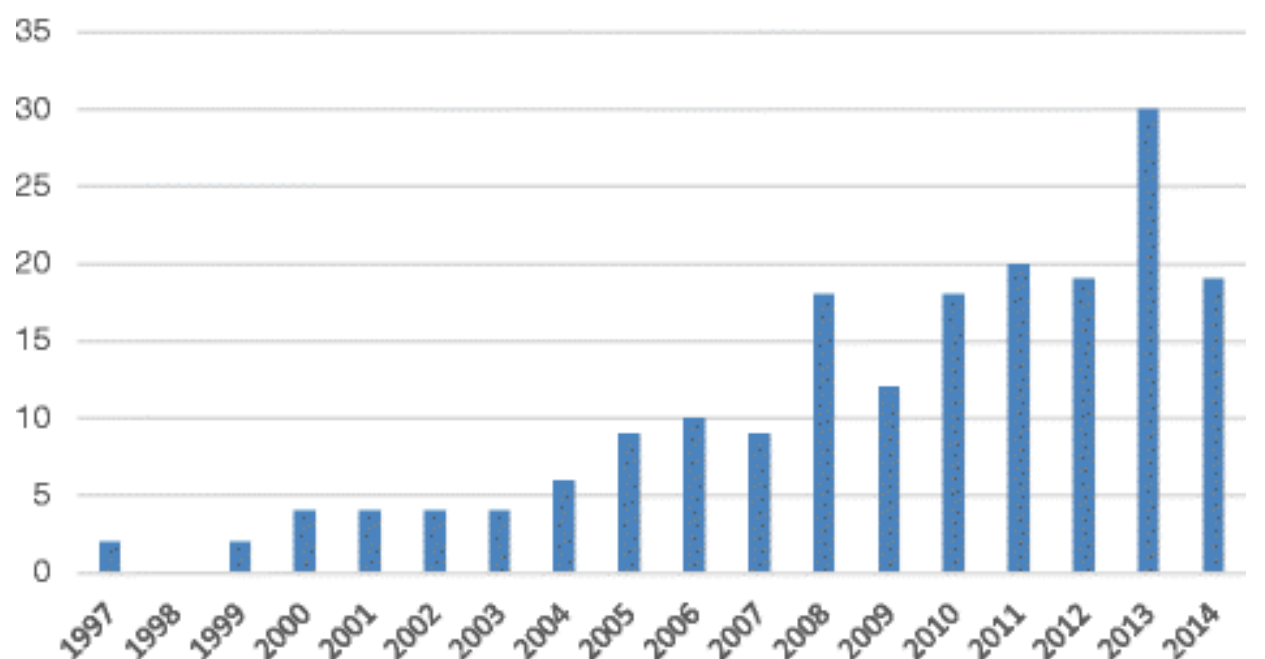

Fig 1: Sample articles on the identity of mathematics published by year https://images.app.goo.g1/Ya2pj7uzN5HnNUjZ6

Articles have been published in 85 different journals, only 19 of these Mathematics Education journals. However, $94(50 \%)$ of the articles were published in these mathematics journals. For example, there were 18 articles in Mathematics Education Studies, 15 articles in Mathematics Education Research Journal, 10 articles in Mathematics Teacher Education and Mathematics Education Journal, and eight articles in Mathematics Learning Journal.

Authors who followed the implications of all things considered made astoundingly clear the speculative packaging from which they were taken, anyway not by and large the choice of that particular theoretical packaging. A couple of makers were unequivocal in their own definition, and the data got was sensible for their perception of character and the results were unsurprising with the main definition (Chronaki) (Epstein, Mendick, \& Moreau). However, this degree of theoretical coherence has not been developed across the range of publications. No definition of identity has been given in some articles at all. However, this degree of theoretical coherence has not been established across a broad variety of publications (Esmonde) (Boaler; Gee). In some posts, no definition of identity has been given at all. However, this degree of theoretical coherence has not been developed across a large range of publications (Hossain, Mendick, \& Adler). No definition of identity has been given at all in some articles.

\section{Defining identity}

Identity may be narrowly described as participatory, narrative, discursive, psychoanalytic or performative. These methods of characterizing personality consider the social setting as a positive character, and each is thought about in the writing science instruction. The indistinct idea of personality building implies that any order is an emotional activity. Others can and have, assembled character implications differently (Black et al.). The accompanying area offers an examination of implications with a restricted arrangement of models. These references were chosen from the more extensive example to feature the hypothetical setting and the differentiating and clashing presence of the character implications in the articles analyzed(Harré \& Van Langenhove). I decided to incorporate here articles which were more clear with respect to their position characterizing personality (Hegedus \& Penuel).

Participatory identity refers to identity concepts that look at how identity is built by involvement and interaction in a social community. Many writers with this view draw from Wenger's (1998) notion of a culture of practice or a figurine worlds (Gleason; Holland \& Lachicotte). Boaler's work utilizes the two networks of training and figured universes to guess about the setting in which understudies build up their ways of life as arithmetic students(Boaler)(Stinson \& Bullock).Solomon (2007b) applies Wenger's (1998) social nature of personality, which incorporates commitment, creative mind and arrangement as methods of having a place, to investigate characters of college understudies (Solomon, Lawson, \& Croft). In other work, (Solomon et al.)joins Wenger's model with (Gee)our sorts of personality in her investigation. Her later work has progressively utilized crafted by (Holland \& Lachicotte)applying rambling situating to understanding students' advancement of delicate personalities (M. E. Goos \& Bennison) and furthermore utilizing Bakhtin's hypothesis of dialogism (Black, Mendick, \& Solomon) (Grootenboer)likewise utilizes Wenger's methods of having a place. In later work, she 
takes a gander at access and occasions to take on essential jobs and at open doors for self-articulation (Nasir \& Hand). Continuously, her consideration has been on issues of force and character for these understudies(Bruner). (Bartholomew, Darragh, Ell, \& Saunders)work in like manner shows up particularly significant for those investigating into pre-organization and juvenile teachers experiences of transforming into an instructor(M. Goos) (Friedrichsen, Lannin, Abell, Arbaugh, \& Volkmann)similarly as in-organization teachers' experiences in master improvement programs that function as organizations of preparing (Graven). The idea of figured universes may similarly be applied to explore on pre-and in-administration instructors.

\section{Discussions}

Slicing through these huge classifications, one more perspective on personalities is to make a move or creation, yet whether character is an instrument, or something we have inside ourselves (Gutiérrez).It recognizes social and monetary and socio-political by asserting that those beginning from a social and financial gathering consider personality to be something that we do as opposed to as something that we may be. In doing as such, she causes to notice a huge dissimilarity found in the conversation of character in arithmetic instruction (Gutiérrez) (Graven).To comprehend the differentiation between these perspectives, it is imperative to take a gander at the setting to the term character. Erikson was the focal figure in the dispersion of the term [identity] (Graven). He instituted the term emotional meltdown, yet in addition characterized a previous personality emergency as having happened during adolescence(Erikson). His vision of personality incorporates the idea of acquiring a focal and stable character. The normal utilization of the word personality can be gotten from this Eriksonian point of view.

Huge numbers of the essential scholars taken from arithmetic training specialists would coordinate their ideas in the Meadian see. Personality is generally consented to be a few or to be spoken to in the plural. Moreover, these unmistakable scholars approach character as far as intercession instead of securing. (Butler) sees identity as not an object, but a constant becoming (pp. 153-4). (Holland \& Lachicotte)Characterize way of life as selfseeing, however keep on depicting personality making measures (p. 3), which treat credibility as an action word.(Gee) It asserts that personality makes an offer to be perceived as a particular sort of individual. They all portray way of life as an activity. Also,, (Boaler)considers personality to be including a relationship with information development;(Sfard \& Prusak)liken character with the recounting a story, an activity.

(Whaley) Notwithstanding, spans the securing activity partition, characterizes way of life as an allowance of faith based expectations (something that can be procured) and furthermore takes a gander at personality when utilizing science to change the states of one's life (activity). A portion of the current writing utilized definitions that clarified that character is something we do. This can be found in the utilization of terms, for example, character work, discussing way of life as something we use as a cycle, or while depicting way of life as established or performed. The individuals who utilize the terminology of character work are keen on the various and frequently clashing personalities that individuals develop (Chronaki \& Matos)use this term to describe teacher change in the context of technology use (Graham \& Selmer).

(Walshaw)It recognizes character and personality; character being the term to comprehend the mental parts of self and personality being what is molded according to the social setting. In spite of the fact that utilizing both mental and sociological perspectives in their examination, these creators position personality development immovably in the sociological area.

\section{Conclusions and future directions}

This paper intends to arrange the manner in which we talk about characters in the science training society. Despite the fact that by focusing on ideas and hypothetical structures, I have distracted from a few other huge central focuses that may have been recommended in its place. Specifically, this examination featured the interests of the westernized world over those of specialists in different fields. Personality is probably going to be the main issue on the planet, the worry of specialists in nations where quality instruction isn't at issue, and there is an advantage of dissecting the relationship of physical and local gatherings to science. Second, in this post, I include propagated a division inside the personality writing of science training, and I might want to concur that all polarities are risky. There are obviously, originations of recognizable proof which don't presumably find a way into some camp (Martin's work is a model). This sociological perspective of character offers us a chance to decipher individuals' view of arithmetic learning and educating in an unexpected way; it gives us something new. We likewise stretch out the person's focal point to examine issues of importance, social groupings and force. It exists at the time of the presentation and as it is perceived. What's more, character is the result of the cycle of acknowledgment, regardless of whether it is self-ID or self-recognizable proof by others. This perspective on 
distinguishing proof holds the watcher as a main priority consistently as a definitive identifier and permits us to perceive the manners by which force is practiced in this affirmation. The understanding of way of life as a demonstration, a presentation that could possibly be acknowledged as wanted, is a helpful future way for study. It is toward this path that Identity Analysis has a ton to bring to the table.

\section{REFERENCES}

1. Andersson, A. (2011). A "curling teacher" in mathematics education: Teacher identities and pedagogy development. Mathematics Education Research Journal, 23(4), 437-454.

2. Bartholomew, H., Darragh, L., Ell, F., \& Saunders, J. (2011). 'I'ma natural and I do it for love!': exploring students' accounts of studying mathematics. International Journal of Mathematical Education in Science and Technology, 42(7), 915-924.

3. Bernstein, B. (2000). Pedagogy, symbolic control, and identity: Theory, research, critique (Vol. 5): Rowman \& Littlefield.

4. Bishop, J. P. (2012). "She's always been the smart one. I've always been the dumb one": Identities in the mathematics classroom. Journal for Research in Mathematics Education, 43(1), 34-74.

5. Black, L., Mendick, H., \& Solomon, Y. (2011). Mathematical relationships in education: Identities and participation: Routledge.

6. Black, L., Williams, J., Hernandez-Martinez, P., Davis, P., Pampaka, M., \& Wake, G. (2010). Developing a 'leading identity': The relationship between students' mathematical identities and their career and higher education aspirations. Educational Studies in Mathematics, 73(1), 55.

7. Boaler, J. (1999). Participation, knowledge and beliefs: A community perspective on mathematics learning. Educational Studies in Mathematics, 40(3), 259-281.

8. Boaler, J. (2000). Multiple perspectives on mathematics teaching and learning (Vol. 1): Greenwood Publishing Group.

9. Boaler, J. (2002). The development of disciplinary relationships: Knowledge, practice and identity in mathematics classrooms. For the learning of mathematics, 22(1), 42-47.

10. Bruner, J. S. (2009). The process of education: Harvard University Press.

11. Butler, J. (1988). Performative acts and gender constitution: An essay in phenomenology and feminist theory. Theatre journal, 40(4), 519-531.

12. Chazan, D., Brantlinger, A., Clark, L. M., \& Edwards, A. R. (2013). What Mathematics Education Might Learn from the Work of Well-Respected African American Mathematics Teachers in Urban Schools. Teachers College Record, 115(2), n2.

13. Chronaki, A. (2005). Learning about 'learning identities' in the school arithmetic practice: The experience of two young minority Gypsy girls in the Greek context of education. European Journal of Psychology of Education, 20(1), 61.

14. Chronaki, A. (2011). "Troubling" essentialist identities: Performative mathematics and the politics of possibility Children, development and education (pp. 207-226): Springer.

15. Chronaki, A. (2013). Identity work as a political space for change: The case of mathematics teaching through technology use. Paper presented at the Proceedings of the seventh international Mathematics Education and Society Conference.

16. Chronaki, A., \& Matos, A. (2014). Technology use and mathematics teaching: Teacher change as discursive identity work. Learning, media and technology, 39(1), 107-125.

17. de Freitas, E. (2008). Troubling teacher identity: Preparing mathematics teachers to teach for diversity. Teaching education, 19(1), 43-55.

18. Epstein, D., Mendick, H., \& Moreau, M.-P. (2010). Imagining the mathematician: Young people talking about popular representations of maths. Discourse: Studies in the Cultural Politics of Education, 31(1), 45-60.

19. Esmonde, I. (2009). Ideas and identities: Supporting equity in cooperative mathematics learning. Review of Educational Research, 79(2), 1008-1043.

20. Friedrichsen, P., Lannin, J., Abell, S., Arbaugh, F., \& Volkmann, M. (2008). Examining incoming identities in an alternative certification program in mathematics and science. EURASIA Journal of Mathematics, Science and Technology Education, 4(2), 169-182.

21. Gee, J. P. JP 2000-2001.“. Identity as an Analytic Lens for Research in Education." Review of Research in Education, 25, 99-125.

22. Gee, J. P. (2014). An introduction to discourse analysis: Theory and method: Routledge.

23. Gleason, P. (1983). Identifying identity: A semantic history. The journal of American history, 69(4), 910-931.

24. Goos, M. (2013). Sociocultural perspectives in research on and with mathematics teachers: a zone theory approach. $Z D M, 45(4), 521-533$. 
25. Goos, M. E., \& Bennison, A. (2008). Developing a communal identity as beginning teachers of mathematics: Emergence of an online community of practice. Journal of Mathematics Teacher Education, 11(1), 41-60.

26. Graham, M., \& Selmer, S. (2011). A Rhizomatic Analysis of Preservice Teacher Learning in Literacy and Mathematics. International Journal of Learning, 17(11).

27. Graven, M. (2003). Teacher learning as changing meaning, practice, community, identity and confidence: The story of Ivan. For the learning of mathematics, 23(2), 28-36.

28. Grootenboer, P. (2013). The praxis of mathematics teaching: developing mathematical identities. Pedagogy, Culture \& Society, 21(2), 321-342.

29. Gutiérrez, R. (2009). Embracing the inherent tensions in teaching mathematics from an equity stance. Democracy and Education, 18(3), 9-16.

30. Gutiérrez, R. (2013). The sociopolitical turn in mathematics education. Journal for Research in Mathematics Education, 44(1), 37-68.

31. Harré, R., \& Van Langenhove, L. (1999). The dynamics of social episodes. Positioning theory: Moral contexts of intentional action, 1-13.

32. Hegedus, S. J., \& Penuel, W. R. (2008). Studying new forms of participation and identity in mathematics classrooms with integrated communication and representational infrastructures. Educational Studies in Mathematics, 68(2), 171-183.

33. Heyd-Metzuyanim, E., \& Sfard, A. (2012). Identity struggles in the mathematics classroom: On learning mathematics as an interplay of mathematizing and identifying. International Journal of Educational Research, 51, 128-145.

34. Holland, D., \& Lachicotte, W. (2007). Vygotsky, Mead, and the new sociocultural studies of identity. The cambridge companion to vygotsky, 101-135.

35. Holstein, J. A., \& Gubrium, J. F. (2001). Institutional selves: Troubled identities in a postmodern world. New York.

36. Hossain, S., Mendick, H., \& Adler, J. (2013). Troubling "understanding mathematics in-depth": Its role in the identity work of student-teachers in England. Educational Studies in Mathematics, 84(1), 35-48.

37. Kaasila, R., Hannula, M. S., \& Laine, A. (2012). "My Personal Relationship Towards Mathematics Has Necessarily Not Changed But..." Analyzing Preservice Teachers'mathematical Identity Talk. International Journal of Science and Mathematics Education, 10(4), 975-995.

38. Mead, G. H. (2011). GH Mead: a reader: Routledge.

39. Nasir, N. i. S., \& Hand, V. (2008). From the court to the classroom: Opportunities for engagement, learning, and identity in basketball and classroom mathematics. The Journal of the Learning Sciences, 17(2), 143-179.

40. Sfard, A., \& Prusak, A. (2005). Telling identities: In search of an analytic tool for investigating learning as a culturally shaped activity. Educational researcher, 34(4), 14-22.

41. Solomon, Y., Lawson, D., \& Croft, T. (2011). Dealing with 'fragile identities': resistance and refiguring in women mathematics students. Gender and Education, 23(5), 565-583.

42. Stinson, D. W., \& Bullock, E. C. (2012). Critical postmodern theory in mathematics education research: A praxis of uncertainty. Educational Studies in Mathematics, 80(1-2), 41-55.

43. Walshaw, M. (2013). Post-structuralism and ethical practical action: Issues of identity and power. Journal for Research in Mathematics Education, 44(1), 100-118.

44. Whaley, K. A. (2014). Gliding through time toward equitable mathematics. Mathematics Teaching in the Middle School, 19(8), 478-485. 